\title{
As imagens digitais como matriz poética da composição cênica
}

Digital images as poetic grid for scenic composition

Natália SOLDERA ${ }^{1}$

\section{Resumo}

O artigo examina espetáculos teatrais, que têm como fator comum a presença de imagens digitais como matriz de composição de suas poéticas. Pretende-se observar aproximações e afastamentos entre essas criações, evidenciando que a presença de tecnologias de imagem não determina uma única linguagem ou aproximação da cena teatral, mas pode proporcionar múltiplas possibilidades ativas de jogo.

Palavras-chave:

teatro e imagens digitais; criações intermediais; matérias de composição da cena.

Abstract:

The article examines plays, which have as common factor the presence of digital images as part of the composition grid of their poetic. It intendes to observe similarities and distances between these creations, showing that the presence of digital images do not determine a single language or approach to the theatrical scene, but can provide multiple opportunities for active interactions.

Keywords:

theater and digital images; intermedial creations; scenic composition materials.
1. Professora da Faculdade de Artes do Paraná (FAP/ UNESPAR) e mestre em Artes Cênicas pelo Programa de Pós-graduação em Artes Cênicas da Universidade Federal do Rio Grande do Sul, com dissertação intitulada O Processo de Composição da Cena a Partir da Noção de Intermedialidade. Contato: nataliasoldera@hotmail.com 
Este escrito propõe um cruzamento entre duas práticas cênicas, a fim de verificar possíveis comprometimentos da cena teatral intermedial. A partir da observação de duas cenas de espetáculos e grupos distintos, que têm em comum a presença de imagens digitais como matriz da sua composição poética, pretende-se investigar como estas podem apresentar semelhanças e especialmente diferenças em suas mundologias ${ }^{2}$. Compreendendo, desta forma, que a presença das tecnologias de produção e reprodução de imagem na cena não pressupõe uma linguagem determinada, podendo promover múltiplas possibilidades de interação com a cena teatral e dialogar de diversas formas com o contexto social contemporâneo.

Para tal, foram escolhidas uma cena do espetáculo Le Projet Andersen da Companhia canadense Ex-Machina, dirigida pelo encenador Robert Lepage e outra do espetáculo Flicker do Big Art Group, grupo nova-iorquino de teatro. Ambas companhias têm por característica a constante presença de imagens digitais em seus espetáculos. Robert Lepage é, desde os anos 80, referência de poética intermedial, tendo experimentado em seus espetáculos diversos mecanismos e múltiplas possibilidades de emprego de tecnologias. Já o Big Art Group, com uma história recente, tem como característica principal o desnudamento das tecnologias de produção e reprodução de imagem na cena.

$$
* * *
$$

Tendo sido escrito, dirigido e atuado por Robert Lepage The Andersen Project conta a história de um compositor canadense convidado a escrever o libreto de uma ópera infantil baseado em um conto de fadas de Hans Christian Andersen. O espetáculo foi realizado em 2005, a convite da coroa dinamarquesa para celebrar o bicentenário do autor Hans Christian Andersen. Além da referência a sua própria posição enquanto artista, o espetáculo se desenrola sobre a temática recorrente, para o encenador, de viagens e descoberta de novos lugares e apresenta múltiplos recursos de orquestração entre cena e imagens digitais na composição dos espaços dramáticos. Segundo Marta Isaacsson em seu artigo Le Projet Anderson, Lepage e a performance da imagem técnica: "a mídia audiovisual é, nesse espetáculo, um fazedor de espaços" (2010, p.65). A cena do espetáculo escolhida para esta análise exemplifica o uso da imagem digital como compositora de espaços. Nesta cena, o personagem aparece sentado sobre um amontoado de malas e aos poucos a imagem digital surge, sobreposta à composição cênica já estabelecida. Essa imagem - de postes de luz ao longo de uma estrada - é projetada em looping e em movi-
2. Mundologias: Exploração e criação do universo latente do projeto criativo. Por meio de estratégias concretas, trabalhamos os temas, atmosferas, códigos, corporeidades, linguagens e contextos relacionados à montagem, uma atividade que supõe simultaneamente descoberta e invenção, forjando um repertório para a criação. Acontecem pela realização de experiências, já que é a experiência que conforma o mundo. (FAGUNDES, 2011, p. 4) 
mento, dando a impressão ao espectador de estar viajando em um trem, observando os postes ao longo da estrada pela janela. É com esta composição que Lepage constrói o espaço do trem onde o personagem faz uma viagem. É interessante notar que a composição ganha força por duas razões: primeiro porque neste espetáculo Lepage faz uso de uma tela em formato côncavo que propicia a fusão entre as imagens do ator e do vídeo, nesta cena o ator está posicionado literalmente dentro da tela, e ainda, porque nenhuma das imagens apresenta-se de forma completa, é a fusão entre as duas imagens incompletas que produz a imagem da cena ${ }^{3}$.

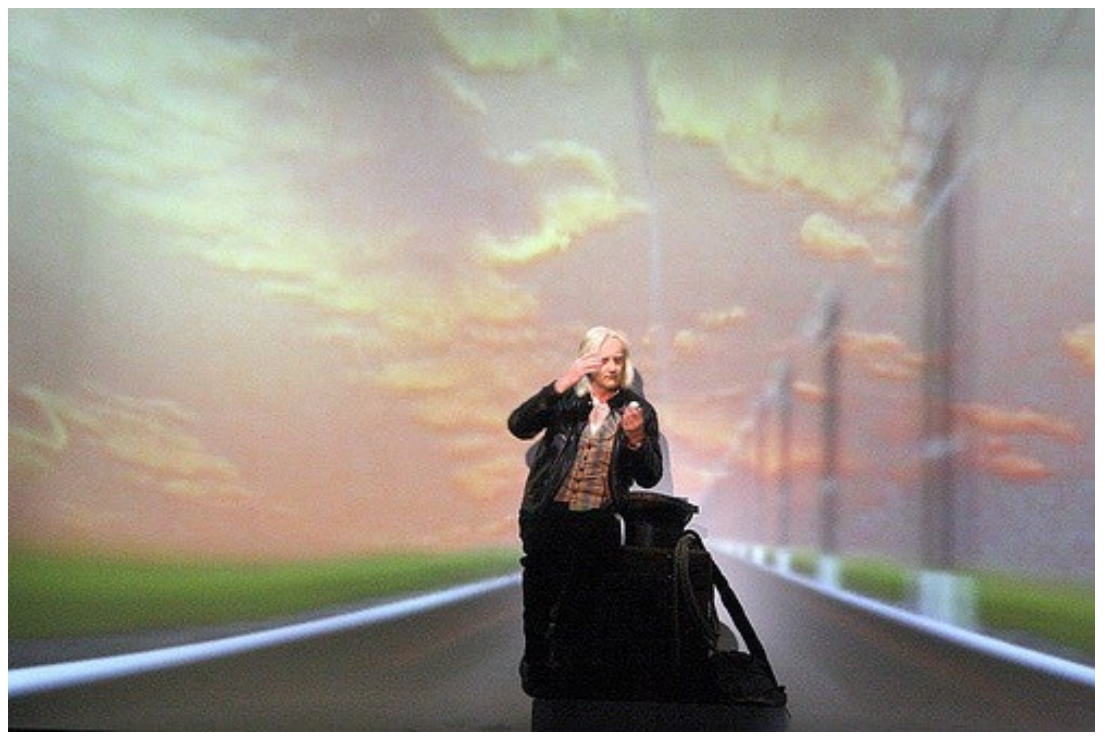

(The Andersen Project. Cena do trem)

Do grupo nova-iorquino Big Art Group o espetáculo Flicker integra a trilogia de espetáculos desenvolvida a partir da técnica de Real Time Film, por meio da qual o grupo desenvolve espetáculos que são compostos com a premissa da execução de um filme em tempo real, no momento do acontecimento do espetáculo. Para isso o grupo conta com uma cenografia composta praticamente por um set de filmagem: diversas câmeras dispostas pelo palco, fundos infinitos próprios para execução da técnica cinematográfica de chroma key e grandes telas para projeção do filme editado e transmitido em tempo real. Desta forma, o palco aparece materialmente dividido entre espaço da ação cênica dos atores e espaço da imagem fílmica. No caso do espetáculo Flicker essa divisão é acentuada, pois são fixadas três telas de projeção que cobrem toda a extensão do palco na frente da ação dos atores. Esta disposição da tela corta o corpo dos atores ao meio, deixando visível apenas a parte superior, servindo também como recurso de desaparecimento dos corpos em cena. A coexistência das imagens acontece de forma conflituosa, a correria da cena reflete a lentidão da performance cênica perante a velocidade
3. "Entendemos por imagem aberta aquela que se mostra incompleta em relação ao referente extracênico a ser evocado, ou seja, o objeto filmado constitui somente um fragmento de um elemento maior de referência. Assim, temos a projeção de imagens de postes de rede em movimento ao longo de uma estrada, texturas de troncos de árvores, a parede de uma estação de metrô". (ISAACSSON, 2010, p. 65) 
dos cortes da edição do audiovisual e, muitas vezes, múltiplos atores são necessários para composição de uma única imagem ou de um único personagem do filme. Os espectadores vivenciam o conflito da apresentação de um filme em uma grande tela, tendo a composição do mesmo filme sendo encenada atrás. O conflito de estar no teatro assistindo à produção de um filme e o esforço necessário para assistir à performance cênica dos atores por trás de todos os equipamentos e seduções tecnológicas.

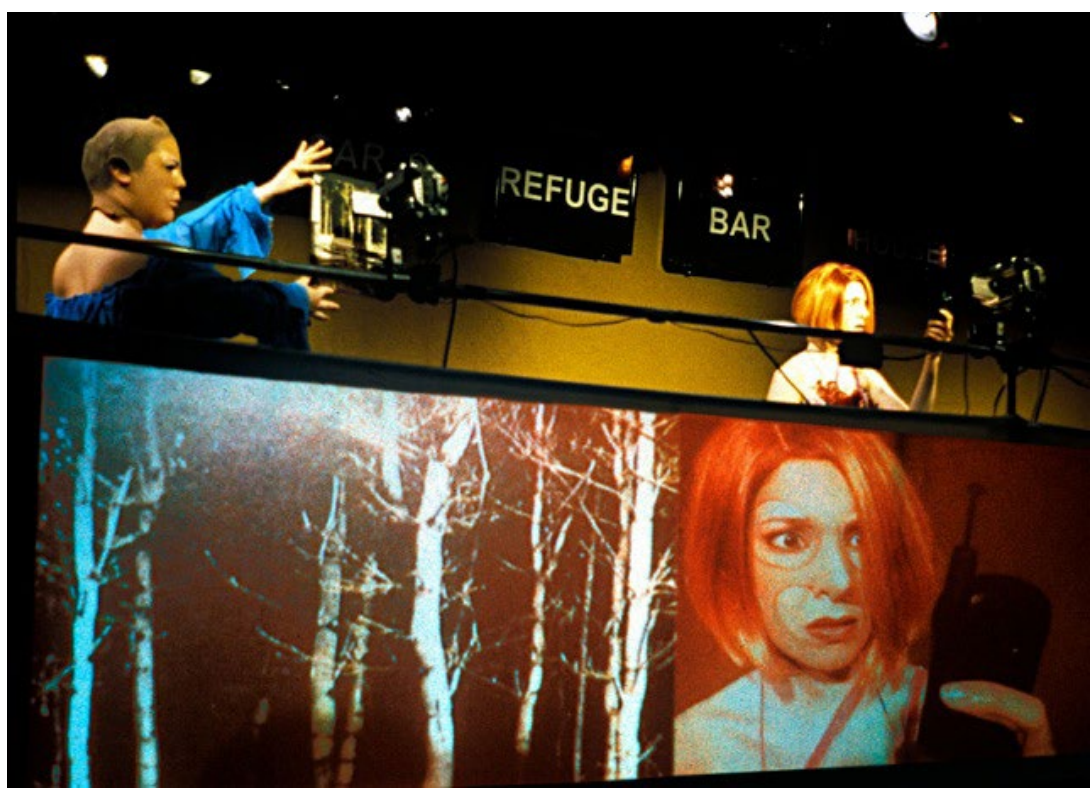

Jacob Gallagher-Ross, no artigo Big Art Group Brings the Noise, propõe uma relação entre as composições do Big Art Group em seus espetáculos de Real Time Film com algumas das propostas do encenador Bertold Brecht:

Seus métodos teatrais descendem de Brecht: dissecando minuciosamente o aparato da manufatura da imagem moderna, eles apresentam as discrepâncias entre corpos vivos no palco e seus doppelgangers na tela como uma representação das muitas formas de transubstanciação da cultura mediática. ${ }^{4}$

Este desnudamento dos mecanismos de composição da imagem fílmica e o conflito da cena pautado na relação de fricção entre as ações dos atores e a composição do filme colocam o espetáculo Flicker, do Big Art Group, em oposição à complementariedade mediática apresentada por Robert Lepage.

$$
* * *
$$

Sendo a poíesis ${ }^{5}$, segundo Dubatti, o local onde se concretiza a relação entre a entidade teatral e o mundo, por meio de
(Flicker)

4. Their theatrical methods are descended from Brecht: opening the apparatus of modern image-manufacturing to dissecting scrutiny, they take the discrepancies between live bodies onstage and their onscreen doppelgangers as a figure for media culture's many forms of transubstantiation" (GALLAGHER-ROSS, 2010, p. 55)

5. a poíesis: caracterizada por um salto ontológico que acontece em oposição à vida cotidiana e instaura um espaço de fricção entre o mundo do acontecimento teatral e o mundo real. A poíesis é o aspecto que diferencia o teatro de outras manifestações com teatralidade. (DUBATTI, 2009, 25). 
um salto ontológico, tomaremos as indicações de Dubatti sobre a poíesis e a teremos como foco inicial de análise das cenas intermediais escolhidas. A partir da compreensão de como as tecnologias de produção e reprodução de imagem contribuem para a configuração destas duas poíesis, tentaremos identificar alguns mecanismos que evidenciem as distintas maneiras de emprego destas tecnologias em ambos os espetáculos teatrais.

Em Flicker a poiésis teatral se configura em um ambiente de interdependência e constante fluxo entre dimensão real e ficcional da cena. A cena não se torna autônoma da realidade cotidiana, pelo contrário, ela se encontra em constante atrito entre real e ficcional, sendo que este atrito evidencia a dimensão da própria realidade cotidiana em detrimento de uma outra realidade ficcional. O espectador presencia não um outro mundo poético, mas a tentativa daqueles corpos de comporem um filme diante de filmadoras. Nem mesmo a estória deste filme está posta em primeiro plano na dramaturgia da cena. Sendo assim, observamos que a poiésis do espetáculo é constituída da relação estabelecida entre a performance dos atores (que estão em nível performativo) e o filme produzido por meio desta performance, cuja projeção constitui toda metade inferior da boca de cena. Estabelece-se uma interdependência entre a performance dos atores, que é organizada e executada totalmente em relação aos equipamentos tecnológicos e o filme.

Podemos compreender que em Flicker, as imagens digitais são fundamentais para a configuração da poiésis do espetáculo, não aparecendo apenas como um elemento complementar. As imagens digitais neste espetáculo são ferramentas geradoras e atuantes do conflito central do espetáculo. Mesmo que o filme projetado, composto em tempo real, narre uma estória com uma série de eventos interligados, o conflito ao qual o espectador se vê atrelado é o conflito promovido pelas coreografias, adequações e ilusões da performance em cena na composição do filme. De que forma a performance é transportada para o filme? Como as câmeras em cena limitam, recortam, dividem os corpos dos atores? Como a edição manipula a imagem da performance cênica em imagem fílmica? São estes jogos que constituem o conflito central do espetáculo.

A interação entre performance cênica e imagem projetada na composição da poiésis do espetáculo The Andersen Project acontece de forma diferente. Levando em consideração a cena selecionada, observamos que a imagem fílmica aparece complementando um jogo já anunciado pelo ator e pelas circunstâncias dramáticas do espetáculo. Marta Isaacsson enfatiza que: "A mídia artificial, na verdade, deixa de constituir um
6. Según la propuesta de la Filosofía del Teatro, no puede haber poíesis si la nueva forma no se diferencia, distancia y autonomiza del régimen de la realidad cotidiana (y su extensión em el mundo), si no instala su próprio régimen y se ofrece a la vez como complemento y ampliación, "mundo paralelo al mundo". (DUBATTI, 2009, p. 99) 
suporte autorreferencial para se tornar um meio no qual a representação do ator se desenvolve." (2010, p. 71). Há também uma relação de interdependência de imagens (da performance cênica e imagem digital), porém esta relação não chega a configurar um conflito ou um atrito. As imagens técnicas estão em favor da ação do ator, compondo em acordo e não em discordância como na cena de Flicker. Assim, no espetáculo de Lepage, podemos observar a constituição da poièsis por meio da complementariedade entre performance e imagens digitais.

Estas diferenças estéticas evidenciam o discurso defendido pelos dois espetáculos com relação a presença de novas tecnologias na cena e na vida. Lepage suaviza as fronteiras entre corpo e tecnologia e evidencia a fluidez com a qual transitamos e co-habitamos os mundos on-screen e off-screen. O próprio Lepage declara que utiliza as tecnologias de produção de imagem em seus espetáculos justamente porque as considera não mais espetaculares em si mesmas, enquanto evoluções tecnológicas, mas como parte integrante da linguagem do homem contemporâneo. Por serem parte da vida em cena estas podem ganhar novos valores poéticos. Enquanto que, o Big Art Group expõe o espectador ao choque das escolhas e das substituições midiáticas, apresentando um espetáculo no qual é demandado um esforço do espectador para visualizar e acompanhar a performance cênica dos atores. Isso evidencia, a partir do ajustamento da ação dos performers à composição de um filme, a padronização da percepção cultural sob os moldes da rápida edição audiovisual e televisiva.

Como aspectos que sintetizam a diferença na relação estabelecida pelos espetáculos com as tecnologias de produção e reprodução de imagem, apresentaremos: a disposição das telas de projeção, o tipo de imagem projetada e o papel do ator em cena.

Ambos espetáculos apresentam um modo de operação da projeção de imagens em cena distinto do convencional, que seria um ciclorama branco ao fundo da caixa cênica7. Lepage utiliza em seu espetáculo, como citado anteriormente, uma tela branca em formato côncavo que permite que o ator e os objetos cênicos se fundam à tela. Disposta no fundo do palco, quase como um fundo infinito, a tela proporciona uma fusão das imagens performativa e fílmica, colaborando para o sentido de síntese e fluidez entre imagens. O Big Art Group, por sua vez, coloca sua tela de projeção na boca de cena, do chão até o meio da abertura pela qual o espectador assiste a cena, escondendo $50 \%$ da área vertical de atuação. Desta forma, os atores têm seus corpos cortados ao meio e só aparecem do quadril para cima, como num recorte cinematográfico de plano americano. O grupo utiliza o espaço escondido como coxia, desaparecendo
7. Aliás, uma das razões da desconfiança do teatro, em acolher as técnicas de imagem no âmbito do espetáculo, está no fato de que tradicionalmente a projeção das imagens se realiza sobre uma tela plana compondo espaços cenográficos semelhantes àqueles do telão pintado, modelo de cenografia já bastante ultrapassado na história do teatro, por não permitir a interação dos corpos dos atores. (ISAACSSON, 2010, p. 69) 
por detrás da tela em jogos de ilusão produzidos ao longo do espetáculo. Esta disposição da tela de projeção das imagens evidencia a competição e o conflito entre as imagens performativa e fílmica. Em nenhum momento elas estão em acordo e a expectação é convocada a assistir esse trânsito entre imagens.
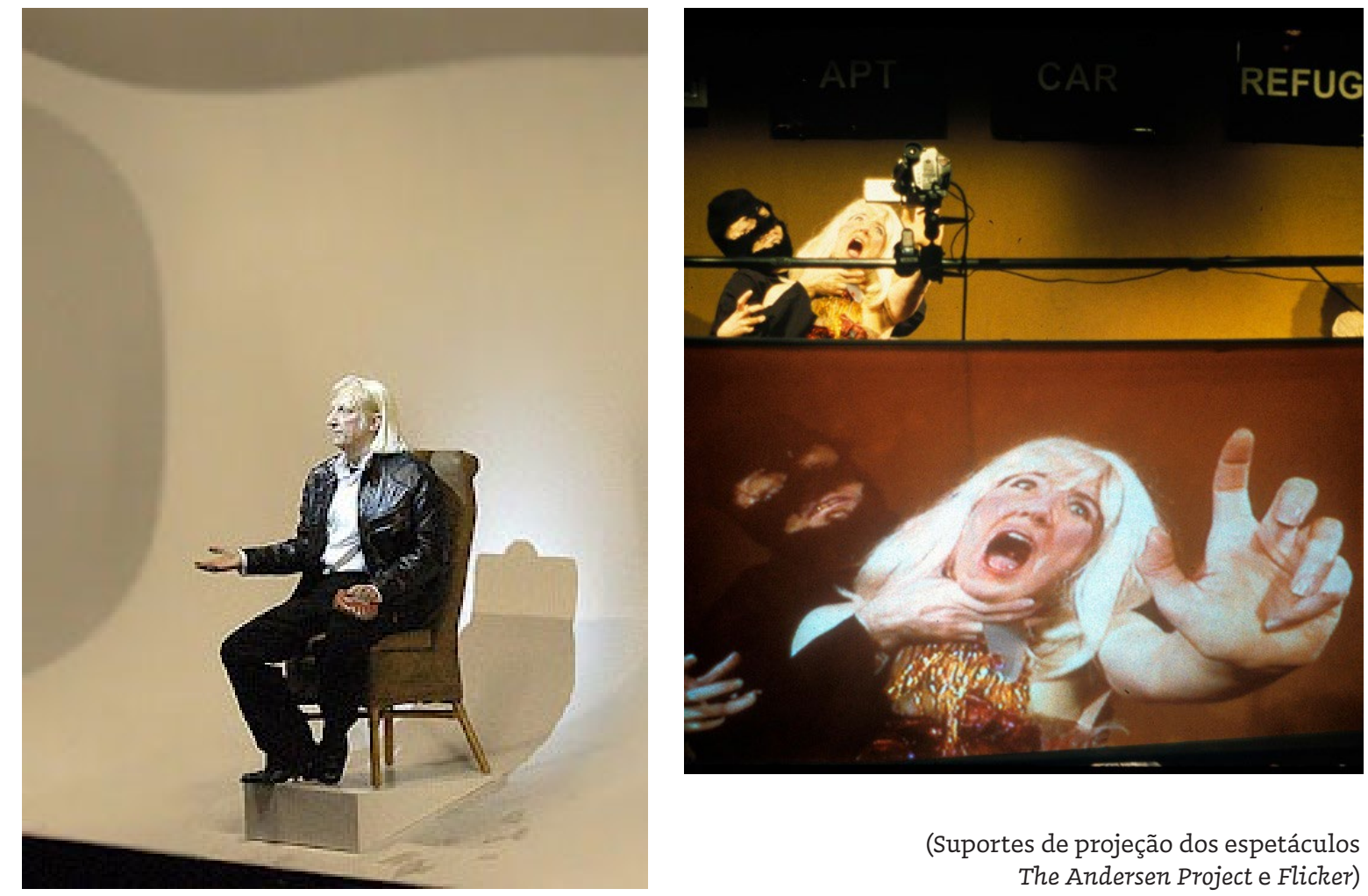

(Suportes de projeção dos espetáculos The Andersen Project e Flicker)

Quanto à especificidade das imagens projetadas observamos que em The Andersen Project são geralmente projetadas imagens pré-gravadas, que participam do jogo através de um processo de aperfeiçoamento e sincronia entre ações do ator e tempo da imagem. No caso da cena escolhida, não há necessidade de uma sincronia perfeita entre as ações do ator e as imagens projetadas, pois os postes em movimento compõem o espaço no qual a ação acontece. Num segundo momento nesta mesma cena, as imagens dos postes em movimento se transformam, ganham cores e seu movimento é acelerado. Esta mudança serve como uma espécie de "deixa" para a ação do ator, que mobilizado pela mudança da imagem pré-gravada também inicia uma alteração em sua ação. Em outras cenas neste mesmo espetáculo as imagens pré-gravadas estão diretamente ligadas à ação do ator. Quando o personagem está parado em frente a imagem de uma estação de metrô, ele retira um spray do bolso e faz a ação de pichar a fachada da estação. A projeção completa a ação do ator, revelando em sincronia com a ação a pichação na parede. 


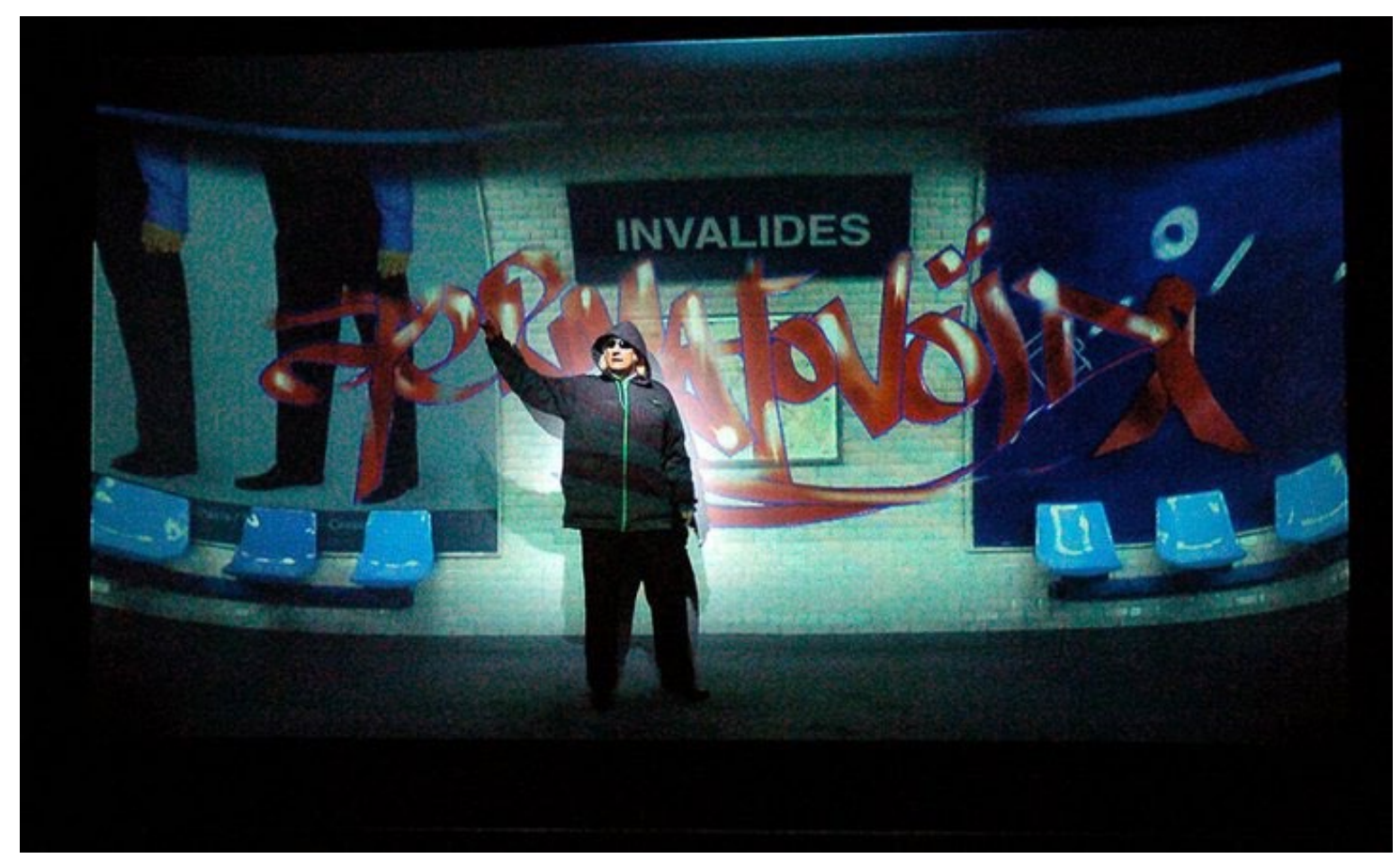

(The Andersen Project. Cena do metrô)

Em Flicker as imagens projetadas são sempre produzidas ao vivo. $O$ espectador tem presente na cena e em simultaneidade o referente e o material fílmico editado. Toda a estrutura de composição do espetáculo é baseada no constrangimento da performance dos atores, diante das câmeras, para a produção perfeita da imagem fílmica. Há, neste caso, uma sincronia que deve ser perfeita entre o tempo das ações dos atores e a espacialização destas ações, para que elas componham em tempo real o filme projetado. Esse constrangimento na composição das imagens em tempo real acontece porque a performance dos atores não é em nenhum momento independente, ela está condicionada ao tempo fílmico e ao enquadramento das câmeras. Segundo Gallagher-Ross, esse jogo promove uma reação de desconfiança sobre a realidade dos corpos dos atores, que em cena aparecem como sombras da imagem fílmica. Além disso, a simultaneidade das ações apaga a distinção entre referente e referencial e o espectador tem a percepção embaralhada entre qual das imagens é a original e qual é a reprodução.

As situações no palco acontecem condicionadas pelas imagens, expectativas e convenções derivadas da televisão e do filme, e desaparecem novamente em sequências fílmicas editadas em tempo real. O que é a cópia e o que é o original; qual é o material fonte e qual é a reprodução gravada - estas são questões não resolvidas e permanentes no decorrer do espetáculo. ${ }^{8}$

8. The situations onstage arrive conditioned by images, expectations, and conventions derived from television and film, and vanish again into video sequences pieced together in real time. What is the copy and what is the original; what is the source material and what is the recorded reproduction - these are permanently unsettled questions throughout the piece. (GALLAGHER-ROSS, 2010, p. 67) 
A situação cênica na qual se encontram os atores do espetáculo Flicker, confinados em um espaço de plano americano cinematográfico e restringidos à coreografia milimetricamente engendrada para composição do filme em tempo real, é determinante para o entendimento do espaço e do discurso da ação dos atores neste espetáculo. O recorte dos corpos, tanto pela tela de projeção quanto pelo enquadramento das câmeras e pelo próprio jogo cênico de esconder e mostrar o corpo, revela a submissão da performance do ator aos recursos tecnológicos em cena. Toda a relação dos corpos dos atores passa pela mediação da tecnologia, quando os atores se tocam no filme eles não estão se tocando no palco. A edição do filme, por diversas vezes, compõe um só corpo a partir do braço de um ator em frente a uma câmera e a mão de outro ator em frente a outra câmera, além disso, os atores em cena não têm gênero, todos fazem papéis masculinos e femininos ${ }^{9}$. O humano perde sua identidade e se torna mais um equipamento de composição do filme, tão importante quanto a maquinaria de câmeras e de edição de imagem. Essa escolha não é ingênua e não menospreza o papel do ator no espetáculo, mas evidencia os problemas da dominação da percepção pelas linguagens televisiva e cinematográfica. Esse discurso ganha potência quando ao final do espetáculo ${ }^{10}$, pela primeira vez e por um breve momento, toda maquinaria é retirada de cena e os corpos de todos os atores se colocam imóveis em frente ao espectador, como uma pausa forçada para que o humano possa ser visto em meio a toda a correria, recortes e multiplicidades da vida contemporânea.

Já no espetáculo The Andersen Project o ator desempenha papel central na composição cênica. As encenações de Robert Lepage têm como característica a importância do jogo do ator na cena como transformador de objetos, de cenografias e das imagens fílmicas. Assim como em Flicker, a situação cênica na qual o ator se encontra promove o modo de relação entre performance e imagem projetada. Em The Andersen Project vemos o ator no centro da cena, integrado à tela de projeção (que aparece como um invólucro da sua ação) e jogando com imagens pré-gravadas de natureza aberta - ou seja, que não comunicam um sentido completo, que têm necessidade da ação do ator para compor. Ao contrário da relação anterior, na qual os atores têm suas ações submetidas à produção das imagens fílmicas, neste espetáculo, as imagens fílmicas têm seu sentido transformado e definido pelo jogo do ator na cena.

Em ambos espetáculos, mesmo que em sentidos opostos, notamos que há uma interdependência entre a performance dos atores e as imagens fílmicas no acontecimento cênico.
9. The implications of these moments of recognition are ambivalent - on the one hand, the video images seem to create virtual bodies that transcend racial and gender differences, beautiful monsters free from the constraints of prescribed representations (after all, if at first we didn't notice the differences, maybe they're not as essential as we think they are). In the radical democracy of the camera lens, before editorial intervention, all bodies are equal - technology sees in a more egalitarian way than we do. But this emancipatory view is countered by the abstraction and violence of the image-making process: bodies are being chopped up and promiscuously reassembled, Frankenstein-like, onscreen before us. (GALLAGHER-ROSS, 2010, p. 70)

10. Cena final do espetáculo Flicker, descrita de maneira muito bela por Gallagher-Ross em seu artigo sobre a companhia: "All at once, this scene of woe is displaced by a startling vision: the entire company of actors, glimpsed all together for the first time, are now running towards the camera, all identically costumed like one of the woebegone teenagers. Suddenly the lights shift, and a warm amber glow turns the videoscreens below transparent; the performers stop moving, and for a fleeting, arresting moment, we finally see the vantage that has been refused us all through the piece: the human form, in its unaltered figural integrity, and diversity of possible shapes, in golden silhouette. For this tiny interval, no cameras block our gaze, no images drag its focus, and we are free to look on one thing only. But the lights are already dimming, the performers are vanishing into the dark, and this fugitive glimmer of wholeness is gone almost as soon as it appeared.". (GALLAGHERROSS , 2010, p. J1) 
Podemos notar ao longo desse exame que as poéticas têm em comum a presença das tecnologias de produção e reprodução de imagem como matéria fundamental da composição cênica e que, ainda assim, articulam discursos e estéticas cênicas distintas, reforçando que a presença das imagens digitais na cena teatral não enforma uma linguagem ou um discurso. Estes dois exemplos em comparação também demonstram que as tecnologias de imagem podem ser agenciadoras do espaço, no caso de Lepage, e do conflito cênico, no caso do Big Art Group, evidenciando um caráter de matéria de composição cênica adquirido por estas tecnologias dentro das artes da cena. 
DUBATTI, Jorge. Cartografia Teatral: Introdución al Teatro Comparado. Buenos Aires: Atuel, 2008.

DUBATTI, Jorge. Filosofia Del Teatro I: convivio, experiencia, subjetividad. Buenos Aires: Atuel, 2007.

FAGUNDES, S. Patrícia. O processo de ensaios como mecanismo de relações: um dispositivo festivo. Anais da VI Reunião Científica da ABRACE. Porto Alegre, 2011.

ISAACSSON, Marta. Le Projet Anderson, Lepage e a performance da imagem técnica. Revista Poiésis, Niterói, n 16, p. 63-73, Dez. de 2010.

GALLAGHER-ROSS, Jacob. Image Eaters: Big Art Group Brings the Noise. TDR/The Drama Review, Cambridge, v. 54, n. 4, p. 54-80, 2010.

\section{IMAGENS:}

Imagens do espetáculo The Andersen Project, disponiveis em: <http://lacaserne.net/index2.php/exmachina/gallery/the_ andersen_project/\#id=album-11\&num=0 >. Acesso em 25/08/2015. Imagens do espetáculo Flicker, disponíveis em: <http://bigartgroup.com/work/flicker/>. Acesso em 25/08/2015.

\section{VÍDEOS:}

Big Art Group: Flicker. Disponível em: <http://www.youtube. com/watch?feature=player_embedded\&v=n78Kx5tmZB4>. Acesso em: 25/08/2015.

Ex-Machina: The Andersen Project. DVD em acervo da pesquisa Cena e Intermedialidade, coordenada pela professora Dra. Marta Isaacsson. 